\title{
Transient phonemic codes and immunity to proactive interference
}

\author{
GERALD TEHAN \\ University of Southern Queensland, Toowoomba, Queensland, Australia \\ and \\ MICHAEL S. HUMPHREYS \\ University of Queensland, St. Lucia, Queensland, Australia
}

\begin{abstract}
Empirical data indicate that when memory for subspan lists of taxonomically related material is tested immediately after study, prior experience with lists involving the same material has no effect upon recall or recognition. In six experiments, we explored the possibility that immunity to proactive interference (PI) is related to discriminative information that is provided by transient phonemic codes. In these experiments, we manipulated the strength of phonemic codes as well as their presence or absence. Immunity to PI was found only when it was presumed that a phonemic representation of the target items existed and that information provided discriminative information. In all other cases, PI was observed. The finding that PI effects correspond with the manipulation of phonemic information in a principled fashion provides strong evidence for the role of phonemic codes in producing short-term PI effects.
\end{abstract}

One of the universally accepted characteristics of shortterm-memory performance is that forgetting is extremely rapid. The basis for such an assertion traditionally rests on performance characteristics observed in the BrownPeterson paradigm (Brown, 1958; Peterson \& Peterson, 1959). On each trial in this task, subjects are first presented with a small number of items for later recall. Then they are presented with a distractor activity, which is aimed at preventing rehearsal of the memory items for varying retention intervals prior to recall. When the subjects are tested after very short retention intervals, their memory for the list items is near perfect. However, as the retention interval increases, they rapidly forget the target items. When the probability of recalling the items is plotted against retention interval, a negatively accelerating forgetting curve results, with performance asymptoting when the retention interval is around $20 \mathrm{sec}$. There are, however, conditions in which this pattern of events does not occur. Keppel and Underwood (1962) demonstrated that on the very first Brown-Peterson trial there is little forgetting, irrespective of the retention interval involved. In fact, they showed that the traditional Brown-Peterson forgetting curve gradually emerged over four or five trials. Keppel and Underwood's data tended to rule out ex-

This research was supported by Australian Research Council Grant 634 to the second author. The first four experiments reported here are part of the first author's doctoral dissertation at the University of Queensland. We would like to thank James Chumbley, Jeff Summers, Graeme Senior, and three anonymous reviewers for helpful comments on a previous draft of this manuscript. Reprint requests should be addressed to G. Tehan, University of Southern Queensland, Toowoomba 4350, Australia (e-mail: tehan@usq.edu.au). planations for short-term forgetting such as trace decay (Peterson \& Peterson, 1959) or retroactive interference (Waugh \& Norman, 1965), but indicated the importance of proactive interference (PI).

The importance of $\mathrm{PI}$ in short-term retention is further emphasized in data derived from the "release-from-PI" paradigm, in which the materials across a number of Brown-Peterson trials come from a single category (e.g., animals). In this situation, performance generally deteriorates across trials, but returns to near-original levels of performance when the materials change on any subsequent trial (e.g., flowers) (Wickens, Born, \& Allen, 1963).

The role of PI in the Brown-Peterson task seems to be so pervasive that Crowder $(1982,1989)$ has argued that "a theory of Brown-Peterson forgetting has to be a theory of how proactive inhibition works in this task" (Crowder, 1989, p. 275). The likelihood that such a theory will be developed is complicated by the fact that there are occasions when short-term-memory performance appears to be immune to the effects of PI (Halford, Maybery, \& Bain, 1988; Humphreys \& Tehan, 1992; Wickens, Moody, $\&$ Dow, 1981). Consequently, a theory of PI should explain performance in situations in which PI is observed, as well as situations in which immunity is observed. The first aim of the current paper is to provide some experimental data that we hope will illuminate our understanding of how PI works in short-term retention. The primary focus, however, is on the conditions that produce immunity to PI.

\section{Immunity to PI}

The exploration of immunity to PI began with a study by Wickens et al. (1981), who devised a task that com- 
bined the essential features of the release-from-PI paradigm and the Sternberg probe recognition task. The task involved presenting blocks of three trials; in each block, material from a single taxonomic category was used. On each trial, memory for a two- or four-item list was tested via a probe, which was presented either after a 2 -sec unfilled retention interval (immediate test) or after a 12$\mathrm{sec}$ filled retention interval (delayed test). Wickens et al. (1981) found that on an immediate test, probe reaction times (RTs) were equivalent for probes on the first (lowPI) trial and third (high-PI) trial in each set, indicating that PI had no effect upon performance. However, on delayed tests, probe RTs were markedly slower than those on the immediate tests, and the effects of PI became apparent, in that RTs for the low-PI tests were approximately $35 \mathrm{msec}$ faster than were RTs for the high-PI tests. Halford et al. (1988) used the same paradigm and demonstrated that PI effects were related to subjects' memory spans. On an immediate test of subspan lists, performance was immune to PI. However, on an immediate test of supraspan lists, PI affected performance. Humphreys and Tehan (1992) also found that serial recall of subspan lists (five digits or five letters) was immune to the effects of PI when an immediate test was employed. However, PI emerged after a filled retention interval of approximately $2 \mathrm{sec}$. Dempster and Cooney (1982) provided information that was analogous to Halford et al.'s data, by using an immediate serial position recall task. When the list length was below span, PI had no effect. When the memory set was above span level, the effects of PI on performance were observed.

Generalizing from these studies, it would appear that when memory for short lists of semantically related material is tested immediately after study, prior experience with similar lists has no effect upon recall or recognition. However, if span is exceeded or brief distractor periods are employed before test, prior experience with such material interferes with the recognition and recall of more recent items.

The relationship between immunity to PI and span is probably not coincidental. That is, the short-term mechanisms involved in span may also be responsible for immunity to PI. In fact, Wickens et al. (1981) explain their results by suggesting that, on an immediate test, the list items are in consciousness and hence are uninfluenced by similar items that are no longer in consciousness. On delayed trials, however, the items have to be retrieved from secondary memory, and this retrieval process is affected by PI. Although the specific two-store version of Wickens et al.'s (1981) explanation has been found wanting (Brannelly, Tehan, \& Humphreys, 1989), it is still plausible that some of the processes that operate in immediate recall may be responsible for the immunity to PI that was observed in the previously cited experiments.

\section{The Role of Short-Term Phonemic Codes}

If we accept as a working hypothesis that some process or mechanism involved in span is also responsible for producing immunity to PI, it is still unclear what that process or mechanism might be. Whatever it is, the data indicate that it must be transient. One possibility is the presence of short-lasting phonemic codes. Baddeley (1986) has convincingly demonstrated that phonemic codes and associated articulatory processes are responsible for many of the effects that are observed in span and immediate serial recall. Thus, the registration and maintenance of phonemic information is thought to underlie the effects that variables such as word length, phonemic similarity, suppression, modality of presentation, and unattended speech have on immediate serial recall. In addition, Penney (1989) has provided evidence that short-term phonemic information is involved in quite a diverse range of other short-term retention tasks. More importantly, Craik and Levy (1976) have persuasively argued that, although there is evidence for the use of non-speech-based codes in short-term retention, only the speech-related codes are truly transient. The key empirical findings underlying these assertions are that, in immediate serial recall, extralist intrusions tend to sound like the forgotten item (Conrad, 1964), and that lists of phonemically similar words tend to be harder to recall than lists with dissimilar sounding words (Baddeley, 1966; Conrad, 1965). The transience of these codes is evident in that after filled retention intervals ranging from about $2 \mathrm{sec}$ to no more than $10 \mathrm{sec}$, the phonemic intrusion effect (Conrad, 1967; Estes, 1973) and the phonemic similarity effect (Hall, Wilson, Humphreys, Tinzmann, \& Bowyer, 1983; Tell, 1972) are eliminated.

With regard to the coding issue, we make the further assumption that phonemic codes serve as a supplement to other available information (Crowder, 1989). We assert that longer lasting central codes that provide information about the semantic nature of the items, category membership, and so on, also play an essential role in shortterm-memory performance. The build-up and release from PI that occurs with the change in semantic categories is an obvious example of the role that these central codes play in short-term memory. With this latter assumption in mind, the present experiments are concerned with the way in which phonemic and central code information influence the likelihood that the effects of PI either will or will not be observed in short-term recall.

Logically, for PI to occur, the representations of interfering and target items must be present at retrieval and there must be some problems with discrimination. At the present time we have no firm ideas concerning the discrimination process. ${ }^{1}$ However, with regard to the issue of representation, we suggest that in both the short-term and the long-term domains, the central representations of the target and interfering items are present. PI in the short-term domain is in one sense unique, in that it is possible for phonemic representations of the items to be present as well. The data concerning phonemic codes indicate that phonemic representations are very susceptible to retroactive interference (Nairne, 1988, 1990). Consequently, the phonemic representation of a particular item will survive only for brief periods if other phonemic representations are generated by subsequent 
activity. In effect, we assume that phonemic information will be limited to the most recent three or four items studied. Our working assumption is that the presence of phonemic information is crucial in producing immunity to PI, in that the addition of phonemic information to available central information makes an item very distinctive and thus easily discriminable. By way of analogy, one can consider driving at dusk on a gloomy winter's night. In heavy approaching traffic, all the cars tend to seem alike until one car switches on its headlights. With the lights on, that car becomes very distinctive and easily discriminable from the cars that have their lights off. We suggest that in most short-term-memory situations, the combination of phonemic and central information will make an item more distinctive than the presence of central information alone. In such situations, immunity to PI should be observed.

The analogy of cars with their headlights on is also useful for suggesting the conditions under which immunity to PI should not be observed. We have already suggested that if none of the cars have their headlights on, discrimination is difficult. Consequently, if there is no phonemic representation of the target item, PI should be observed. Moreover, if all the cars have their lights on, discrimination will again be difficult. If a phonemic representation of an interfering item is generated and maintained in addition to the phonemic representation of a target item, PI would again be expected. Finally, consider a single car that has its headlights on at noon on a bright, sunny summer's day. In this case, the light still provides the same information, but because of background factors, that information is not as distinctive. We believe that there are conditions in which phonemic information for the target item alone is available, but it does not provide distinctive or discriminating information. In these situations, PI should again be observed.

If our analysis is correct, it follows that PI should be observed under three sets of conditions: (1) when there is no phonemic information about the target items; (2) when there is phonemic information, but it does not discriminate between target and interfering items; and (3) when there is phonemic information for interfering as well as target items. In fact, the only time that immunity to PI should be observed is when there is phonemic information for the target item alone and that information does discriminate between the target and interfering item.

The following experiments were conceived with these assumptions in mind. To foreshadow what emerges, it appears that immunity to PI in short-term recall is observed only under conditions in which it is plausible that discriminative phonemic information concerning the target item is present. In all other conditions, the effects of interfering items are present.

\section{GENERAL METHOD}

In the following experiments, subjects studied a series of oneor two-block trials; each block contained four words. They were instructed that, at all times, they were to remember the most recent block. This meant that if the trial was a two-block trial, they were to forget the first block and concentrate on remembering the second block. Memory was tested either immediately or after a 2 -sec filled retention interval that involved the verbal shadowing of two four-digit strings. PI was manipulated by the presence or absence of an item (or items) in Block 1 that was similar to the target item (or items) in Block 2.

\section{Subjects}

In each of the six experiments, except Experiment 5, 20 firstyear psychology students from either the University of Southern Queensland or the University of Queensland participated for course credit. None of the students participated in more than one experiment. In Experiment 5, where retention interval was a between-subjects variable, 40 first-year students participated.

\section{Materials}

The materials for the experiments were derived primarily from rhymes (Walling, McEvoy, Oth, \& Nelson, 1994) and taxonomic category norms (McEvoy \& Nelson, 1982) generated by Nelson and his colleagues at the University of South Florida.

In Experiment 1, four instances were selected from each of 40 different rhyme categories. The construction of the 40 four-word study trials commenced with a randomization of the 40 categories. The first 20 categories that emerged from the randomization process served as the pool for the phonemically similar lists. The items within each category were randomly assigned to the four serial positions. The 20 phonemically dissimilar lists were constructed by randomly assigning the items from the remaining 20 rhyme categories to different lists. This process was carried out for each subject.

In the remaining experiments on each trial, the participants studied either one- or two-block trials. The one-block trials always served as filler trials to ensure that the subjects attended to the first four words that they studied. The critical trials in all the experiments were the two-block trials, because it was on these trials that PI was manipulated. The second block always contained the target item or items. When PI was introduced, a similar item or items also appeared in the first block. In the no-interference conditions, the items in the first block were always unrelated to the target items in the second block.

Thus, in Experiment 2, in which serial recall was required, 8 instances were selected from each of 30 different taxonomic categories (McEvoy \& Nelson, 1982). PI was manipulated by presenting material from the same category in both blocks. An interference trial started with the presentation of the category label in uppercase. This was followed by a random selection of 4 of the 8 instances from the category, presented in lowercase. The second block started with the presentation of the category label, followed by the remaining 4 instances from the category. A typical interference trial might have looked something like "PROFESSION nurse teacher doctor prostitute PROFESSION psychologist lawyer dentist engineer." The structure of the no-interference trials was identical to that of the interference trials; the only difference was that the materials in the first and second blocks were different. A typical nointerference trial might have looked something like "FLOWER rose petunia daisy lily PROFESSION psychologist lawyer dentist engineer." Half the lists in each condition were tested immediately, and half were tested after a $2-\sec$ filled delay.

The remaining four experiments all required cued recall instead of serial recall. Following the presentation of the items, a category cue appeared in uppercase, and the subjects were requested to recall the item, from the most recent block, that had been an instance of the specified category. On these trials, a single target item appeared in the second block among three unrelated filler items. On the interference trials, a second item from the same category as that of the target item appeared among three unrelated filler items in the first block. Thus, a typical interference trial might have looked 
like "READY meal pig engine road ! Image sheep dock starch FARM ANIMAL." On the control trials, all four items in the first block were unrelated to the target item-for example, "READY meal lip engine road ! Image sheep dock starch 01578733 FARM ANIMAL."

In constructing these trials, separate word pools were generated for filler and target items. There was no overlap between the category membership of filler and target items. Thus, the filler items were always unrelated to the critical items. For the critical items, two instances were sampled from each category. In order to maximize the chance of finding PI on an immediate test, the interfering foll in Block 1 was usually a dominant member of the category, and the Block 2 target was usually a relatively weak member of the category. On the interference trials, foil and target always appeared in the same serial position in their respective blocks. ${ }^{2}$ To avoid possible primacy and recency effects, the target (and foil) appeared equally often in the second and third serial positions only.

The assignment of materials to condition and the order of the trials in each experiment were randomized for each subject. The latter ensured that the subjects never knew in advance whether the trial would be a one-block filler trial or a two-block interference or control trial.

\section{Procedure}

Each trial began with a READY sign, displayed on the computer monitor for $2 \mathrm{sec}$. The study items were then displayed individually at a rate of one word per second, and the subjects were instructed to remain silent (unless otherwise instructed) throughout the presentation of the study items. On two-block trials, a block separator, usually an exclamation mark (!), was presented for $1 \mathrm{sec}$ after the fourth word in the first block and before the first word in the second block. Recall instructions always appeared for $2 \mathrm{sec}$ in uppercase. For serial recall, the word RECALL was used, and in the cued-recall experiments, the category cue was presented. On an immediate test, the cue appeared immediately after the fourth item in the block. On the delayed trials, two four-digit strings appeared on the screen after the fourth word, at the rate of one string per second. The subjects were required to read the digits aloud as they appeared on the screen. The recall cue appeared after this $2 \mathrm{sec}$ of shadowing actıvity. With the appearance of the recall cue, the subjects were requested to either verbally recall the items in their presentation order on serial-recall trials, or, on the cued-recall trials, verbally recall the category instance from the most recent block. The subjects had $5 \mathrm{sec}$ to make a response before the next trial began. The experimenter recorded the subjects' responses (correct recall, order errors, intrusion errors, omissions, etc.) on a hard copy of the subject's input file.

\section{EXPERIMENT 1}

If our assumptions about the importance of phonemic codes in producing immunity to PI are correct, we would argue that PI should be observable after a filled retention interval of a duration sufficient to eliminate the phonemic codes. From the work reviewed earlier, it is clear that the effects attributed to the operation of phonemic codes dissipate within $10 \mathrm{sec}$ (Conrad, 1967; Estes, 1973; Tell, 1972). However, we were interested in shorter intervals. Baddeley (1986) and Schweickert and Boruff (1986) emphasized a 2-sec limitation on the availability of phonemic codes in immediate serial recall. Furthermore, Humphreys and Tehan (1992) demonstrated that, with nonvocalized visual presentation, PI effects emerged after about $2 \mathrm{sec}$ of distractor activity. If phonemic codes are important in producing PI effects, these data would suggest that these codes are not available after $2 \mathrm{sec}$ of distractor activity. Consequently, our expectation was that phonemic similarity would have a deleterious effect upon immediate recall, but would have no effect upon delayed recall.

\section{Method}

The subjects studied 40 one-block trials for serial recall. For 20 trials, the four ttems in each list all rhymed, and in the remaining trials, the items within each block were phonemically dissimilar. Half the trials in each condition were tested immediately, and half were tested after a $2-\sec$ filled delay.

\section{Results and Discussion}

The outcomes of this experiment were as predicted. On an immediate test, the probability of recalling the phonemically dissimilar items in position was .79 , and the probability of recalling the similar items was .70 . On the delayed test, the probabilities of recalling the dissimilar and similar lists were .33 and .32 , respectively.

Planned comparisons confirmed that these observations represent stable characteristics in the data. Phonemic similarity impaired performance on an immediate test $\left[F(1,19)=24.10, M S_{e}=.016\right]$, but did not influence recall after a filled delay $\left[F(1,19)=.15, M S_{\mathrm{e}}=.035\right]$.

The lack of similarity effects on the delayed test do not appear to be due to floor effects. The serial position curves for the two conditions are almost identical in shape. The probabilities of recalling the dissimilar items in position were $.52, .36, .24$, and .21 for the first, second, third, and fourth positions, respectively. The equivalent figures for the phonemic similarity condition were .51, $.32, .22$, and .24 . Thus, even if performance on the last two serial positions is on floor, the early serial positions are not. Floor effects are not responsible for the attenuation of the phonemic similarity effect on a delayed test.

The attenuation of the phonemic similarity effect after a brief filled retention interval suggests that we have established a set of task parameters with which we can confidently make inferences regarding the availability of phonemic information. These same task parameters should enable us to test our assumptions about the role of phonemic information in producing PI effects. Given our explanation for immunity to PI, we expected that on an immediate test the effects of PI would not be evident. However, after a 2-sec filled retention interval, the effects of PI should be readily observable.

\section{EXPERIMENT 2}

\section{Method}

Subjects studied 40 trials; PI was manipulated in 20 one-block filler trials and 20 two-block trials. Half the trials of both types were tested for immediate serial recall, and the other half were tested by serial recall after a $2-\sec$ delay.

\section{Results}

Filler trials. Obtaining interference effects in this and subsequent experiments depended upon the subjects' attending to the first block in the two-block trials. To ensure attention to the first block, one-block trials were presented. 
Performance on the Block 1 trials in this experiment and in all subsequent experiments indicated that the subjects attended to that first block. In Experiment 2, the mean probability of recalling an item in position on an immediate test was .91 , and averaged around the $80 \%$ level across all the other experiments. Serial position effects were consistent with the known patterns associated with visual presentation. We are confident that the subjects attended to the first block, and thus Block 1 performance will not be reported in subsequent experiments.

Two-block trials. The two-block data are summarized in Figure 1.

The critical interference data in this and the following experiments were analyzed by planned comparisons, in which the interference and the no-interference conditions were compared first for immediate test and then for delayed tests. When performance was collapsed across serial positions on immediate tests, there was no evidence of any effect of PI $\left[F(1,19)=0.79, M S_{\mathrm{e}}=.042\right]$. On the delayed tests, however, the effects of PI did emerge. Performance on the interference trials was reliably below that on the no-interference trials $[F(1,19)=$ $\left.6.83, M S_{\mathrm{e}}=.077\right]$.

\section{Discussion}

The absence of PI effects on an immediate test is consistent with prior research (Halford et al., 1988; Humphreys \& Tehan, 1992; Wickens et al., 1981). Finding PI effects after a filled retention interval is also consistent with previous research. The task parameters of Experiments 1 and 2 were equivalent. The subjects were required to remember four words at any given time and were tested either immediately or after $2 \mathrm{sec}$ of shadowing activity. The results of the two experiments suggest that immunity to PI is found when phonemic codes are present, but PI effects emerge and phonemic similarity effects disappear at the same retention interval. These

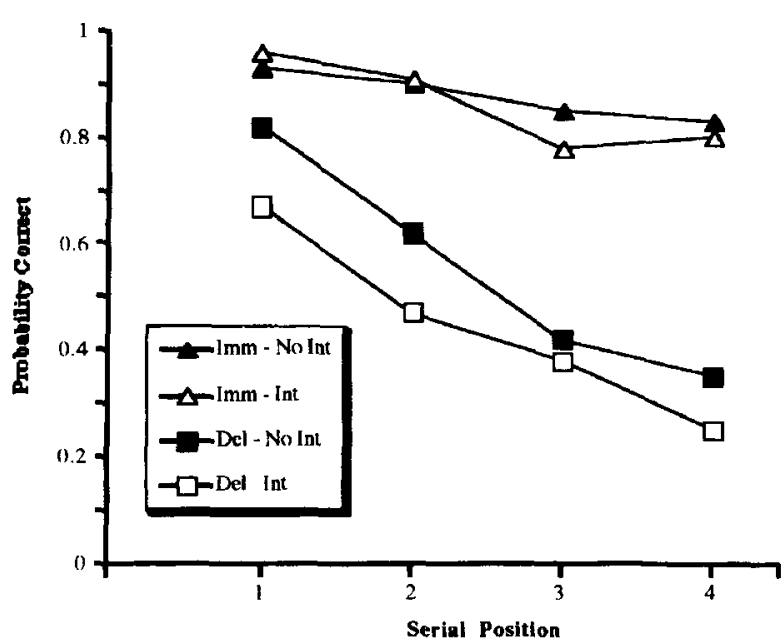

Figure 1. Serial position curves for correct recall of immediaterecall, delayed-recall, interference, and no-interference trials in Experiment 2 . results indicate that our contention that phonemic codes play a role in producing immunity to PI is plausible.

\section{EXPERIMENT 3}

In the following experiments we examined PI effects within the context of a short-term cued-recall task. We changed tasks primarily for two reasons. First, other factors, such as output interference, also play an important role in the standard short-term tasks (Hadley, Healy, \& Murdock, 1992; Nairne, 1990), including the BrownPeterson task (Lewandowsky \& Murdock, 1989). As such, these factors add additional problems to the interpretation of results. The adoption of a short-term cuedrecall task, in which a single list item is cued, ensures that the effects of extraneous variables are kept to a minimum and allows for the easy manipulation of cues. Second, it is important to establish the generality of immunity to PI on an immediate test across as many different short-term tasks as possible.

Experiment 3 was a straightforward replication of Experiment 2 , except that cued recall with a taxonomic cue was required instead of serial recall. The experimental outcomes were expected to be identical to those obtained in Experiment 2.

\section{Method}

There were 72 trials; these consisted of 24 filler trials and 48 two-block trials. Again, half the 24 interference trials were tested immediately, and half were tested after a 2 -sec delay. The same was true of the 24 control trials.

\section{Results}

The subjects' performance at recalling the critical item, given a category cue at retrieval, is summarized in Table 1.

The first planned comparison confirmed that there was no evidence of an effect of PI upon cued recall on an immediate test $\left[F(1,19)=.38, M S_{\mathrm{e}}=.007\right]$. The effects of PI on cued recall did, however, emerge on a delayed test $\left[F(1,19)=22.66, M S_{\mathrm{e}}=.007\right]$.

Three types of error were possible on the cued-recall trials: (1) the subjects could fail to produce any item (omission); (2) they could generate an appropriate category member that did not appear anywhere in the list (extralist intrusion); and (3) they could produce the interfering word from the first block (list intrusion). Table 2 presents the probability of making the different types of errors for each condition.

The essential features of the recall data are replicated in the error data. In the delayed condition, omissions and extralist intrusions seem to be quite similar across all conditions. PI effects are obvious from the large percentage of list intrusions in the interference condition.

\section{Discussion}

With regard to the major concerns of the study, the expected pattern of PI effects did emerge in the data. We have argued that the retrieval process generates central 


\begin{tabular}{|c|c|c|}
\hline \multicolumn{3}{|c|}{$\begin{array}{l}\text { Table } 1 \\
\text { Mean Probability Correct for Recalling the } \\
\text { Block } 2 \text { Target as a Function of Type of Test, } \\
\text { Interference Condition, and Retention Interval }\end{array}$} \\
\hline \multirow[b]{2}{*}{ Condition } & \multicolumn{2}{|c|}{ Retention Interval } \\
\hline & Immediate & Delayed \\
\hline \multicolumn{3}{|c|}{ Experiment 3 (pig sheep FARM ANIMAL) } \\
\hline No interference & .87 & .79 \\
\hline Interference & .85 & .58 \\
\hline \multicolumn{3}{|c|}{ Experiment 4 (wrench bench ENCH) } \\
\hline No interference & .92 & .79 \\
\hline Interference & .85 & .62 \\
\hline \multicolumn{3}{|c|}{ Experiment 5 (cat rat ANIMAL) } \\
\hline No interference & .87 & .57 \\
\hline Interference-nonthyme & .82 & .55 \\
\hline Interference-rhyme & .74 & .54 \\
\hline \multicolumn{3}{|c|}{ Experiment 6 (pig sheep FARM ANIMAL) } \\
\hline \multicolumn{3}{|l|}{ Silent-Aloud } \\
\hline No interference & .88 & \\
\hline Interference & .83 & \\
\hline \multicolumn{3}{|l|}{ Aloud-Silent } \\
\hline No interference & .71 & \\
\hline Interference & .60 & \\
\hline
\end{tabular}

representations of two possible candidates for recall and, at the same time, generates a phonemic representation of the target item alone. On an immediate test, phonemic information is then combined with the central information to facilitate the discrimination of the target item from the interfering item. On a delayed test, PI emerges because, although the central information is available, the phonemic information about the target has been interfered with by subsequent distractor activity. Consequently, there is a reduced ability to distinguish between a target and an interfering item.

Given this explanation of the differing effects of PI with changes in retention interval, it should be possible to observe PI on an immediate test when the phonemic information is present but does not discriminate between a target and a distractor. One situation in which this might occur is when the target and the interfering item are both members of a rhyme category. That is, information about the phonemic characteristics of the target would discriminate between two dissimilar-sounding members of a taxonomic category, but such information would not easily discriminate between two similarsounding members of a rhyme category.

\section{EXPERIMENT 4}

Experiment 4 was a replication of Experiment 3 in all important respects. The only differences were that ending cues were provided at recall, and the interfering and target items had the same ending. ${ }^{3}$ Given our explanation of PI, the predictions are straightforward. On an immediate test, the central representations of two instances of the ending category should be produced, along with a phonemic representation of the target item. How- ever, since this phonemic representation did not strongly discriminate between the target and the interfering item, PI was expected. On a delayed test, PI was expected for the same reasons that it had been expected in the previous experiments-phonemic information had been lost.

\section{Method}

Subjects again studied 48 two-block cued-recall trials under immediate- or delayed-recall conditions. In addition, 20 filler trials were tested via serial recall; 10 were one-block trials that were tested immediately, and 10 were two-block trials in which the second block was tested after a $2-\mathrm{sec}$ retention interval. The procedure in this experiment was identical to that used in Experiment 3. The only difference was that instead of the presentation of a category cue, an ending cue (e.g., ovE) was presented prior to recall.

\section{Results}

The data from the cued-recall trials are summarized and presented in Table 1. The data indicate that ending cues produce somewhat different effects than do taxonomic cues. When the target was tested immediately, the presence of an interfering item in the first block reliably suppressed recall of the target item compared with tar-

Table 2

Probability (Conditional) of Making Various Errors on Block 2 Target Recall as a Function of Interference Condition and Retention Interval

\begin{tabular}{cccc}
\hline & \multicolumn{3}{c}{ Type of Error } \\
\cline { 2 - 4 } & Omissions & $\begin{array}{c}\text { Extralist } \\
\text { Intrusions }\end{array}$ & $\begin{array}{c}\text { List } \\
\text { Intrusions }\end{array}$ \\
\hline
\end{tabular}

Immediate Test

No interference Interference

Experiment 3

Delayed Test

No interference

$.09(.72) \quad .04(.28)$

$.06(.40) \quad .02(.11)$

$.07(.49)$

Interference

$.22(.77) \quad .06(.23)$

$.17(.39) \quad .04(11)$

$.21(.50)$

Immediate Test

No interferenc

Interference

Experiment 4

Delayed Test

No interference

$.03(.40)$

$05(.60)$

$.03(.17) \quad .03(.17)$

$.09(.66)$

Interference

$.06(.25) \quad .15(75)$

$.06(.17) \quad .09(.24)$

$.23(.59)$

Experiment 5

Immediate Test

No interference

$.09(.67)$

$.03(.33)$

Interference-nonrhyme

Interference-rhyme

$.08(.43)$

$.08(.43)$

$.03(.14)$

Delayed Test

No interference

$31(.71)$

$.04(.13)$

$.17(.65)$

Interference-nonrhyme

Interference-rhyme

$.19(.42)$

$.13(.29)$

$.18(.38)$

$.09(.20)$

$.10(.22)$

$.18(.38)$

Experıment 6

Silent Aloud

No interference

$.10(79)$

$.03(.21)$

Interference

$.09(.49)$

$.03(.17)$

$.06(.34)$

Aloud Silent

No interference

$.22(.75)$

$.08(.25)$

Interference

$.09(.21)$

$.04(.09)$

$.18(.39)$

Note-- The probability of makng a particular type of error, an error was made, is presented in parentheses. 
get recall in the no-interference condition $[F(1,19)=$ $\left.4.54, M S_{\mathrm{e}}=.009\right]$. Interference was also apparent when the target was tested after a 2-sec delay $[F(1,19)=15.83$, $\left.M S_{\mathrm{e}}=.018\right]$.

The effects of interference can also be seen in the number of Block 1 intrusions present on the interference trials, as is evident in Table 2 . These intrusions represent a major source of error on both immediate and delayed tests for this condition.

\section{Discussion}

The pattern of PI effects in Experiment 3 emerged in accord with our expectations. Our explanation for why immediate-test performance differed from the pattern of performance in Experiment 3 is simply that, in Experiment 3 , the phonemic code strongly discriminated between the target item and the interfering distractor. In Experiment 4, the phonemic code, although present, no longer strongly discriminated the target from the distractor. That is, the phonemic code may have specified the interfering item as well as the target item. PI on delayed tests was observed in both experiments, because the phonemic codes were no longer present.

Our explanations for the differences on immediatetest performance between Experiments 3 and 4 concern target similarity. That is, we explain the effects in terms of the properties of elicited representations, and not as a function of the different cues. A clear prediction that emerges from such a perspective is that, irrespective of the retrieval cue used, PI should be present on an immediate test any time phonemic codes do not discriminate a target item. Consequently, we would also expect PI on an immediate test in which taxonomic cues were used, but both the target and interfering item rhymed-for example, when cat appears in Block 1, rat is the target item in Block 2, and the cue is ANIMAL. We argue that the phonemic information will not be unique to the target item, and thus the subjects will not be able to use this information to discriminate the target from the interfering foil.

\section{EXPERIMENT 5}

\section{Method}

The materials in this experiment were derived from 30 taxonomic categories. From each category, a target item and two interfering items of equal strengths were selected. One of the interfering items rhymed with the target, and the other did not. ${ }^{4}$ We obtained these categories by going through the University of South Florida rhyme norms (Walling et al., 1994) to find rhyming words that could conceivably be members of the same category. Thus, rake and stake could both be subsumed by the cue GARDENING IMPLEMENT. After we had established 30 taxonomic categories with rhyming instances, we used controlled association procedures identical to those used to generate the University of South Florida norms. Seventy-nine subjects were given the category cue and were instructed to write down the first instance of that category that they thought of. Using this procedure, it was possible to select a nonrhyming instance of the category that had an associative strength that was equal to that of the item selected to be the rhyming interfering instance. It should be stated that because rhyming members of taxonomic categories were uncommon, the vast majority of target and interfering items used in this experiment were very weakly related to the category cue. The cues and instances are presented in the Appendix. The method of construction for each subject's trials was identical to that used in the previous experiments.

The 45 trials in the experiment consisted of 30 two-block trials and 15 filler trials. The 30 two-block trials consisted of 10 nointerference trials, 10 interference trials in which the target and foil did not rhyme, and 10 interference trials in which the target and foil did rhyme. Retention interval was a between-subjects variable in this experiment, whereas it had been a within-subjects manipulation in the previous experiments. Difficulties in establishing an adequate pool of rhymıng instances of taxonomic categories forced this variation in procedure.

\section{Results}

Performance on the cued-recall trials is summarized in Table 1. On immediate-recall trials, the comparison of the nonrhyming interference condition with the nointerference condition confirmed that there were no reliable differences between their means $[F(1,19)=1.16$, $\left.M S_{\mathrm{e}}=.017\right]$. The comparison between the rhyming interference and the no-interference conditions demonstrated that having a rhyming item in the first block did impair performance $\left[F(1,19)=9.00, M S_{e}=.017\right]$. Regarding performance on the delayed trials, it was predicted that there would be no difference between the two interference conditions. The comparison involving these conditions was not significant $\left[F(1,19)=0.01, M S_{\mathrm{e}}=.026\right]$.

The pattern of Block 1 intrusions, presented in Table 2, complements correct-recall performance. Of the subjects who were given immediate tests, 3 did not make any Block 1 intrusions. Of the 17 remaining subjects who did produce at least one Block 1 intrusion, 16 made more rhyme interference intrusions than nonrhyme intrusions, and 1 subject produced a tied score. None of the subjects made more nonrhyme intrusions than rhyme intrusions. On the delayed-recall test, 8 subjects produced more rhyme intrusions than nonrhyme intrusions, 8 produced more nonrhyme than rhyme intrusions, and there were four ties. Clearly the nature of the interfering item had a strong effect upon an immediate test, but had little effect upon a delayed test.

\section{Discussion}

Most of the expected patterns of performance emerged in the data. Interference was present on an immediate test when the two instances on the list were rhyming members of a taxonomic category. When the instances did not rhyme, no effects of the interfering item were observed on target recall. Considering the results of this experiment and those of Experiment 3, it would appear that the presence or absence of PI on an immediate test can be best understood in terms of target similarity effects. That is, if the recall process produces representations of two items that have similar sound characteristics, it is less likely that the target item will be produced than if the two items have dissimilar sound characteristics.

In Experiment 5, performance on the delayed test was not as clean as we would have liked. If one looks at the 
correct-recall measure, it appears that there are no interference effects. However, if one looks at Block 1 intrusions, it is clear that the Block 1 items had a substantial effect upon performance. The deleterious performance in the control condition is probably due to the nature of the categories used and to extremely weak associations that generally existed between the cues and the instances. However, for the present purposes, the critical factor is that the two interference conditions did not differ, as they did on the immediate test. This was the case whether correct recall or Block 1 intrusions were used as the dependent measure.

\section{EXPERIMENT 6}

In the previous experiments, we have focused on the phonemic attributes of the target items and have assumed that a phonemic representation of the interfering item has not been present. Logically, it follows that if a phonemic representation of the interfering item could be generated, we should observe PI on an immediate test. In Experiment 6, we attempted to ensure that, at test, a phonemic representation of the interfering item would also be present.

Most current explanations of short-term recall (Baddeley, 1986; Nairne, 1990; Penney, 1989) argue that auditory presentation produces stronger or more distinctive short-term information than does visual presentation. Furthermore, it appears that this auditorially generated short-term information is not interfered with if subjects are instructed to group items (Ryan, 1969). Grouping items in such a way produces striking within-group recency effects with auditory presentation, but not with visual presentation (Frankish, 1985).

These within-list modality effects are important for the present purposes, because it would appear that they are related to phonemic information. Frick (1989) and Greene (1989) have carried out grouping studies in which phonemically similar lists have been employed. In both data sets, not only was the end-of-list recency effect depressed, but within-group recency was almost nonexistent. Furthermore, Greene's data indicated that, in grouped lists, reading the items aloud in one block tended to suppress the recall of silently read items in a second block.

On the basis of this literature, it might be possible to maintain a phonemic representation of the interfering item, if subjects read the Block 1 items aloud and read the Block 2 items silently. If our guess is correct, at recall there may be a phonemic representation of the interfering item as well as the target item. If such is the case, PI should be observed. If subjects read the Block 1 items silently and the Block 2 items aloud, there should be strong phonemic information available for the target item alone. Under these conditions, we would expect to find immunity to PI.

\section{Method}

Twenty interference trials and 20 no-interference trials were created as for the previous experiments. Ten one-block cued-recall trials were also presented.
Procedure. The procedure in this experiment was very similar to that employed in the previous experıments. The only difference was that the instructions concerning presentation conditions preceded each block. Prior to the presentation of each block, the word ALOUD or SILENT appeared for $1 \mathrm{sec}$. If the cue was ALOUD, the subjects were instructed to read the items aloud as they appeared on the screen. If the cue was SILENT, they were instructed to remain silent throughout the presentation of four items. The instructions came in two orders; if the first block was read aloud, the second block was read silently, or if the first block was read silently, the second block was read aloud. There were immediate tests on all trials.

\section{Results and Discussion}

Performance on the cued-recall trials is summarized in Table 1 . When the first block was read silently and the second block was read aloud, results from the interference condition did not reliably differ from those in the nointerference condition $\left[F(1,19)=1.63, M S_{\mathrm{e}}=.019\right]$. However, when the first block was read aloud and the second block was read silently, PI was observed; performance on the no-interference trials was reliably better than performance on the interference trials $[F(1,19)=$ $\left.5.94, M S_{\mathrm{e}}=.019\right]$.

The error data on the two-block trials is presented in Table 2. The pattern of Block 1 intrusions again complements correct-recall performance. Two of the subjects did not make any Block 1 intrusions. Of the 18 remaining subjects who did produce at least one Block 1 intrusion, 17 made more Block 1 intrusions in the aloud-silent conditions than in the silent-aloud conditions. One subject made one Block 1 intrusion in the silent-aloud condition and none in the aloud-silent condition.

The study conditions were varied in an attempt to alter the strength of phonemic codes by requiring the subjects to read items aloud. The pattern of PI effects appears to confirm the success of such a manipulation, in that the emergence of PI on an immediate test in the aloud-silent condition suggests that we have produced and maintained a phonemic representation of the interfering foil. With the presence of phonemic information for both the target and the interfering item, there are problems in discriminating the target item from the interfering item.

\section{GENERAL DISCUSSION}

The three basic performance characteristics that emerged from the current set of experiments require explanation. First, PI effects are time dependent. That is, they generally emerge only after a brief retention interval. Second, this time dependency of PI is modified by a materials variable. PI does occur on an immediate test if the to-be-remembered word and the interfering word rhyme. This occurs for both ending cues and taxonomic cues. Third, PI effects appear to be sensitive to manipulations that either interfere with or strengthen phonemic codes.

This pattern of performance is consistent with an explanation of PI that is based upon the assertion that phonemic information can provide supplementary discriminative information when combined with central in- 
formation. The relationship between PI effects and phonemic information is indicated in the first two experiments, in which phonemic similarity and PI effects were explored with the same task parameters. Immunity to PI was observed under the task conditions that produced strong phonemic similarity effects. However, PI effects also became apparent under the task conditions in which phonemic similarity effects were attenuated. In the remaining experiments, we attempted to manipulate the strength, the presence, or the absence of phonemic codes. The finding that PI effects corresponded in a principled fashion to the manipulation of phonemic information provides strong converging evidence for the role of phonemic codes in producing PI effects. Although the empirical evidence strongly indicates the influence of phonemic codes in short-term PI, we have ignored the possibility that other explanations of the data are possible. We now turn to this issue.

There are at least two factors involved in our experimental design that may have had an unwarranted impact upon performance. ${ }^{5}$ In Experiments 3, 4, and 6, the interfering word was always a highly dominant instance of the category, and the target item was always a less dominant instance. If the subjects became aware of this fact, it is possible that they could use this information to restrict their answers to the less dominant member. The second methodological issue involves the use of only the second and third serial positions. Again, if the participants became aware of this constraint, they could limit their responses accordingly. The adoption of these strategies should make the task much easier. That is, Block 2 in effect becomes a one- or two-item list instead of a four-item list. If this happened, the current findings are all the more surprising and the effects of the variables being manipulated may well have been underestimated. Furthermore, these strategic explanations explain why immunity to PI might be observed on an immediate test, but they do not explain why modality and rhyming variables should produce differential effects, nor why PI emerges after such a brief retention interval when, presumably, the same strategies could be employed.

In turning to more theoretical alternatives to our explanations, it is possible to attempt alternative explanations for immunity to PI on the basis of different memory structures. Wickens et al. (1981), for example, argue that the differences can be explained in terms of what is in consciousness and what is not. To account for the current data from this perspective, one would have to argue why rhyming items are lost from consciousness more rapidly than nonrhyming items. We can think of no plausible reasons why this should be the case. Furthermore, one would have to specify how modality of presentation affects consciousness. Again, we can think of no reasonable explanation for the modality effect in terms of items being active in consciousness. The pattern of PI effects does not appear to be conducive to explanations that involve items being resident in consciousness or in some type of short-term buffer.
Another frequently proposed alternative involves temporal distinctiveness. A number of researchers have suggested that many of the recency effects that pervade memory tasks can be explained by assuming that recent items are more temporally distinctive than early items (Baddeley \& Hitch, 1974; Crowder \& Neath, 1991; Glenberg \& Swanson, 1986). A perceptual metaphor is usually employed to highlight the essential characteristics of temporal distinctiveness. The metaphor involves an observer looking at a line of telephone poles. The last pole in the line is more easily discriminated from earlier ones if the observer is standing near the last pole in the line rather than if the observer is standing a long distance away from the last pole. To explain performance in the present Experiment 3, it could be argued that the target item in the second block was more temporally distinctive on an immediate test than it was on a delayed test, with the result that discrimination was easier on an immediate test than on a delayed test. In short, from this viewpoint, immunity to $\mathrm{PI}$ is an emergent feature of increased temporal distinctiveness. However, we think that appeals to temporal distinctiveness cannot account for the effect that rhyming targets have. We cannot see how rhyming words are less temporally distinctive than nonrhyming words-an assumption that would have to be made to explain the rhyming effects. In terms of the telephone pole metaphor, we cannot think of any attributes of telephone poles that make them equally distinctive at short and long distances.

An alternative way to evaluate our explanation of shortterm PI effects is to examine the necessity for the assumptions that have been proposed to explain the current findings. We would like to argue that a complete explanation of PI would have to include an assumption involving a distinction between speech-based and central memory codes.

With respect to the involvement of phonemic codes, it is clear that target similarity effects are present in the data. These target similarity effects are observed in materials that are both orthographically and phonemically similar. In opting for a phonemic similarity account and rejecting orthographic similarity as the crucial variable, we are relying primarily upon the demonstrated involvement of phonemic codes in immediate serial recall, their role over short retention intervals in the BrownPeterson task (Conrad, 1967; Estes, 1973; Tell, 1972), and their role in other short-term retention tasks (see Penney, 1989). In contrast to the strong support for the role of phonemic codes, Penney has presented a substantial amount of evidence that indicates that visual codes are unlikely to be used or even generated under the immediate-test conditions employed in the present experiments. The finding that PI effects are sensitive to manipulations that are generally believed to alter the strength or availability of phonemic information provides converging evidence for the role of phonemic codes.

Given the strong evidence for the role of phonemic codes in other tasks, we think that it is reasonable to assume that they also operated in the current short-term 
cued-recall task. Such an assumption has the benefit of explaining the pattern of short-term PI effects as an emergent feature of the operation of other, well-documented, short-term characteristics. From such a perspective, these results are continuous with much of the traditional short-term-memory literature.

In concluding, we would like to return to the issues that prompted this paper. We argue that immunity to PI and the interaction of PI with target similarity and presentation modality must be addressed in any account of PI. Our approach to this problem is to argue for the joint combination of central and phonemic codes. At the present time, we have not specified exactly how this occurs. Solutions to this problem would probably differ, depending upon assumptions about the architecture of memory. However, providing a solution to the problem would not only go a long way toward providing a complete account of PI, but would go a long way toward providing a complete explanation for short-term memory as well.

\section{REFERENCES}

BADDELEY, A. D. (1966). Short-term memory for word sequences as a function of acoustic, semantic and formal simılarity. Quarterly Journal of Experimental Psychology, 18A, 362-365.

BADDELEY, A. D. (1986). Working memory. Oxford: Oxford University Press.

BADDELEY, A. D., \& Hitch, G. (1974), Working memory. In G. H. Bower (Ed.), The psychology of learning and motivation (Vol. 8, pp. 67-89). New York: Academic Press.

BENNETT, R. W. (1975). Proactive interference in short-term memory. Fundamental forgetting processes. Journal of Verbal Learning \& Verbal Behavior, 14, 123-144.

Brannelly, S., Tehan, G., \& Humphreys, M. S. (1989). Retrieval plus scanning: Does it occur? Memory \& Cognition, 17, 712-722

BRown, J. A. (1958). Some tests of the decay theory of immediate memory. Quarterly Journal of Experimental Psychology, 10, 1221.

Chappell, M., \& Humphreys, M. S. (1994). An auto-associative neural network for sparse representations: Analysis and application to models of recognition and cued recall. Psychological Review, 101, 103-128.

Conrad, R. (1964). Acoustic confusions in immediate memory. British Journal of Psychology, 55, 75-84.

ConRaD, R. (1965). Order errors in immediate recall of sequences. Journal of Verbal Learning \& Verbal Behavior, 4, 161-169.

CoNRAD, R. (1967). Interference or decay over short retention intervals. Journal of Verbal Learning \& Verbal Behavior, 6, 49-54.

CraIK, F. I. M., \& LEVY, B. A. (1976). The concept of primary memory. In W. K. Estes (Ed.), Handbook of learning and cognitive processes (Vol. 4, pp. 133-175). Hillsdale, NJ: Erlbaum.

Crowder, R. G. (1979). Audition and speech coding in short-term memory. In J. Requin (Ed.), Attention and performance VII (pp. 321-342). Hillsdale, NJ: Erlbaum.

Crowder, R. G. (1982). The demise of short-term memory. Acta Psychologica, 50, 291-323.

Crowder, R. G. (1989). Modularity and dissociations in memory systems. In H. L. Roediger \& F. I. M. Craik (Eds.), Varieties of memory and consciousness. Essays in honor of Endel Tulving (pp. 271294). Hillsdale, NJ: Erlbaum.

Crowder, R. G., \& NeATH, I. (1991). The microscope metaphor in human memory. In W. Hockley \& S. Lewandowsky (Eds.), Relating theory and data: Essays in honor of Bennet B. Murdock (pp. 111125). Hillsdale, NJ Erlbaum.
Dempster, F. N., \& CoONEy, J. B. (1982). Individual differences in digit span, susceptibility to proactive interference, and aptitude: achievement test scores. Intelligence, 6, 399-416.

Dillon, R. F., \& Thomas, H. (1975). The role of response confusion in proactive interference. Journal of Verbal Learning \& Verbal Behavior, 14, 603-615.

Estes, W. K. (1973). Phonemic encoding and rehearsal in short-term memory for letter strings. Journal of Verbal Learning \& Verbal Behavior, 12, 360-372.

Frankish, C. (1985). Modality-specific grouping effects in short-term memory. Journal of Memory \& Language, 24, 200-209.

FrICK, R. W. (1989). Explanations of grouping in immediate ordered recall. Memory \& Cognition, 17, 551-562.

GlenberG, A. M., \& SWANson, N. G. (1986). A temporal distinctiveness theory of recency and modality effects. Journal of Experimental Psychology: Learning, Memory, \& Cognition, 12, 3-15.

GORFEIN, D. S. (1987). Explaining context effects on short-term memory. In D. S. Gorfein \& R. R. Hoffman (Eds.), Memory and learning The Ebbinghaus Centennial Conference (pp. 153-172). Hillsdale, NJ: Erlbaum.

GREENE, R. L. (1989). Immediate serial recall of mixed-modality lists. Journal of Experimental Psychology Learning, Memory, \& Cognition, 15, 266-274.

Hadeey, J. A., Healy, A. F., \& Murdock, B. B. (1992). Output and retrieval interference in the missing-number task. Memory \& Cognition, 20, 69-82.

Halford, G. S., Maybery, M. T., \& Bain, J. D. (1988). Set-size effects in primary memory: An age-related capacity limitation? Memory $\&$ Cognition, 16, 480-487.

Hall, J. W., Wilson, K. P., Humphreys, M. S., Tinzmann, M. B., \& BoWYER, P. M. (1983). Phonemic-similarity effects in good vs. poor readers. Memory \& Cognition, 11, 520-527.

Humphreys, M. S., \& Tehan, G. (1992). A simultaneous examination of recency and cuing effects. In A. Healy, S. Kosslyn, \& R. M. Shiffrin (Eds.), From learning theory to cognitive processes: Essays in honor of William K. Estes (Vol. 2, pp. 143-159). Hillsdale, NJ: Erlbaum.

KePPEL, G., \& UNderwood, B. J. (1962). Proactive inhibition in shortterm retention of single items. Journal of Verbal Learning \& Verbal Behavior, 1, 153-161.

LeWANDOWsKy, S., \& Murdock, B. B. (1989). Memory for serial order. Psychological Review, 96, 25-57.

MCEvoY, C. L., \& NELSON, D. L. (1982). Category name and instance norms for 106 categories of various sizes. American Journal of Psychology, 95, 581-634.

NAIRNE, J. S. (1988). A framework for interpreting recency effects in immediate serial recall. Memory \& Cognition, 16, 343-352

NAIRNE, J. S. (1990). A feature model of immediate memory. Memory \& Cognition, 18, 251-269.

Penney, C. G. (1989). Modality effects and the structure of short-term verbal memory. Memony \& Cognition, 17, 398-422.

Peterson, L. R., \& Peterson, M. J. (1959). Short-term retention of individual items. Journal of Experimental Psychology, 58, 193-198.

RYAN, J. (1969). Grouping and short-term memory: Different means and patterns of grouping. Quarterly Journal of Experimental Psychology, 21A, 137-147.

SCHWEICKERT, R., \& BORUFF, B. (1986). Short-term memory capacity: Magic number or magic spell? Journal of Experimental Psychology, $12,419-425$.

TELL, P. M. (1972). The role of certain acoustic and semantic factors at short and long retention intervals. Journal of Verbal Learning \& Verbal Behavior, 11, 555-564.

Walling, J. R., McEvoy, C. L., OTH, J. E., \& Nelson, D. L. (1994). The University of South Florida rhyme category norms. Unpublished manuscript, University of South Florida.

Waugh, N. C., \& Norman, D. A. (1965). Primary memory, Psychological Review, 72, 89-104.

Wickens, D. D., Born, G. D., \& Allen, C. K. (1963). Proactive inhibition and item similarity in short-term memory. Journal of Verbal Learning \& Verbal Behavior, 2, 440-445. 
Wickens, D. D., Moody, M. J., \& Dow, R. (1981). The nature of timing of the retrieval process and of interference effects. Journal of Experimental Psychology: General, 110, 1-20.

\section{NOTES}

1. By using the term discrimination, all we want to convey is the generic notion that some process is involved in the ability to choose a target item and reject an interfering item. The most common way that discrimination has been addressed in the PI literature is in terms of trace discrimination. In these studies, PI is seen simply as the subject's inability to discriminate the most recent memory trace from earlier similar traces (Bennett, 1975; Crowder, 1982; Gorfein, 1987). We think it ill advised to adopt this position for two reasons. First, there are data to suggest that this is an overly simplistic response (Dillon \& Thomas, 1975; see also data from the current experiments). Second, the idea of suppressing nontarget responses and selecting a target response is a feature of some connectionist models that assume distributed rather than localized representations (Chappell \& Humphreys, 1994). It is plausible that this type of memory model may provide a better fit of the PI data than the trace discrimination models.

2. Pilot work indicated that the position of the interfering item in the first block had no effect upon the interference effects found

3. Although we have chosen to explore phonemic codes within rhyme categories, our predictions would not change if the items had similar beginnings and were cued with a stem (e.g., wreck, wrench, WRE). Our choice of ending cues rather than stem cue $\pi$ s was based solely on the fact that the norms we had for ending categories were more extensive than those for stem categories.

4. As one reviewer pointed out, we made one error in selecting 1 of the 30 sets of materials. Selecting slime and grit as rhyming and nonrhyming distractors for grime falls to control for the fact that grit and grime also share some phonemic characteristics. Although the vowel characteristics differ, the presence of some overlap means that grit is less likely to be an appropriate control than other selected items.

5. These factors were suggested by an anonymous reviewer of an earlier version of this paper.

\begin{tabular}{|c|c|c|c|}
\hline \multicolumn{4}{|c|}{$\begin{array}{l}\text { APPENDIX } \\
\text { Materials Used in Experiment } 5\end{array}$} \\
\hline \multirow[b]{2}{*}{ Cue } & \multirow[b]{2}{*}{ Target } & \multicolumn{2}{|c|}{ Interfering Instance } \\
\hline & & Rhyme & Nonrhyme \\
\hline TYPE OF DIRT & grime & slime & grit \\
\hline TYPE OF SOUND & ping & sing & music \\
\hline TYPE OF NOISE & clang & bang & hum \\
\hline AMUSEMENT PARK ITEM & slide & ride & swing \\
\hline TYPE OF FOOD & wheat & meat & bread \\
\hline RELATED TO THE HAND & wrist & fist & arm \\
\hline ANIMAL & goose & moose & duck \\
\hline TOY & trike & bike & plane \\
\hline SYNONYM OF UNCOUTH & crude & rude & vulgar \\
\hline COOKING PROCEDURE & broil & boil & fry \\
\hline SMALL WOUND & nick & prick & gash \\
\hline TYPE OF ACCIDENT & smash & crash & plane \\
\hline NOISE FROM MOUTH & squeak & speak & cough \\
\hline PART OF A BODY & loin & groin & breast \\
\hline FARM ANIMAL & hog & $\operatorname{dog}$ & horse \\
\hline MUSICAL INSTRUMENT & lute & flute & $\operatorname{sax}$ \\
\hline BODY MOVEMENT & flick & kick & sway \\
\hline FISHING EQUIPMENT & creel & reel & bait \\
\hline TYPE OF PEST & lice & mice & flea \\
\hline PART OF A HOUSE & wall & hall & lounge \\
\hline HITTING MOVEMENT & whack & smack & thump \\
\hline FOUR-LEGGED ANIMAL & rat & cat & cow \\
\hline PART OF A BUILDING & floor & door & room \\
\hline COOKING ITEM & rice & spice & ladle \\
\hline TYPE OF BIRD & hen & wren & owl \\
\hline GARDENING IMPLEMENT & stake & rake & fork \\
\hline ARTICLE OF CLOTHING & smock & sock & jeans \\
\hline TYPE OF PLANT & reed & weed & ivy \\
\hline MICROSCOPIC ITEMS & sperm & germ & cell \\
\hline DAILY MEAL & brunch & lunch & dinner \\
\hline
\end{tabular}

(Manuscript received December 30, 1993; revision accepted for publication March 7, 1994.) 